\title{
FLÁVIO DE CARVALHO: ARQUEOLOGIA E CONTEMPORANEIDADE
}

\author{
VERONICA STIGGER mostra como a Experiência $n^{\circ} 3$ do artista \\ não se limita a seu caráter emancipatório
}

Era quinta-feira, 18 de outubro de 1956, por volta das três horas da tarde, quando Flávio de Carvalho desfilou pelas ruas do centro de São Paulo com o traje que havia concebido para o homem dos trópicos. Como o evento havia sido anunciado à imprensa, uma pequena multidão, entre jornalistas e curiosos, esperava-o descer de seu escritório na rua Barão de Itapetininga. Dali, o desfile, acompanhado de perto por um número a cada instante maior de pessoas, seguiu pelas ruas Marconi e Sete de Abril, pela praça Ramos de Azevedo e, depois, de volta para o local de onde partiu. Numa época em que os homens vestiam obrigatoriamente calças compridas, camisa e terno (até mesmo os meninos, como podemos ver nas várias fotografias da caminhada), o que mais chamava a atenção na indumentária proposta por Flávio de Carvalho era a incorporação da saia ao guarda-roupa masculino. "Na verdade", escreveu Manuel Bandeira na ocasião, "se tivéssemos juízo e coragem, adotaríamos o traje inventado por Flávio de Carvalho." Mas acrescentou: "Como não temos, chamamo-lo de louco e vaiamo-lo".[1] A confecção do traje era resultado de uma longa reflexão sobre a moda que Flávio vinha desenvolvendo em artigos publicados no Diário de São Paulo, na sua coluna Casa, Homem, Paisagem, sob o título A moda e o novo homem, entre 4 de março e 21 de outubro daquele ano. Após o desfile, Flávio de Carvalho foi até a sede dos Diários Associados, na rua Sete de Abril, e subiu numa das mesas da redação para responder às perguntas dos jornalistas e para melhor expor seu traje aos fotógrafos. Em seguida, retirou-se para vestir o segundo conjunto que criara, também com saia, e voltou para exibi-lo. No dia seguinte, ministrou palestra no Clube dos Artistas e Amigos da Arte, o Clubinho, na qual explanou as vantagens da nova indumentária masculina de verão. Seis dias depois, realizou, também no Clubinho, o Baile do Traje do Futuro. 
O evento como um todo - a reflexão sobre a moda, o desfile, a palestra, o baile e o posterior estudo sobre a recepção do traje que Flávio intentava fazer a partir da "análise psicológica e social do material obtido através da imprensa, que é o espelho da opinião pública do país"[2] - ficou conhecido como Experiência $n^{\circ} 3$. Sua experiência anterior, a primeira, curiosamente chamada Experiência $n^{\circ} 2$ (Flávio de Carvalho nunca esclareceu qual teria sido a sua Experiência $n^{\circ} 1[3]$ ), fora realizada duas décadas antes, mais precisamente em 7 de junho de 1931, quando o artista decidiu cruzar uma procissão de Corpus Christi no sentido contrário, com uma boina verde na cabeça, a fim de estudar a reação dos fiéis, e quase acabou linchado. É por conta principalmente dessas suas "experiências" - que, como alguns trabalhos artísticos das décadas de 1960 e 1970, consistem na combinação da própria ação do artista com uma reflexão sobre esta - que Flávio de Carvalho vem sendo compreendido como um elo entre o moderno e o contemporâneo.

Haroldo de Campos talvez tenha sido o primeiro a apontar o visionarismo de Flávio de Carvalho na dedicatória que lhe fez da primeira edição de Poemas, de Maiakovski, livro de traduções do poeta russo realizado com Boris Schnaiderman e Augusto de Campos, em 1967: "A Flávio de Carvalho, inventor do happening".[4] Quatro anos depois, Décio Pignatari, em Contracomunicação, corroboraria o juízo histórico de Haroldo: “com suas 'experiências' da década de 30”, o artista foi “o precursor do happening no Brasil”. [5] Ainda na década de 1970, Antonio Manuel anotou em texto inédito: "Flávio de Carvalho extrapola seu tempo para encontrar-se com gerações futuras".[6] Na década seguinte, Walter Zanini, no final do texto de apresentação da sala especial de Flávio de Carvalho na 17a Bienal de São Paulo, aconselhou os jovens a prestarem atenção no artista: "As novas gerações, enriquecidas pela problemática conceptual, encontram sem dúvida nesse homem/ideia toda uma riqueza precursora que o torna referência fundamental para nossa atualidade".[7] A partir de então e principalmente na última década, quando a obra de Flávio vem recebendo uma decisiva reavaliação [8], muitos são os que passaram a vê-lo como um precursor da arte contemporânea. Tadeu Chiarelli, em texto para o catálogo da grande retrospectiva do artista em comemoração dos cem anos de seu nascimento, em 1999, sugeriu que um estudo dedicado sobretudo às suas 
experiências "abriria a possibilidade de percebê-lo como um artista que, em certa medida, superou os aspectos mais característicos das performances dadá e surrealistas, apontando para uma prática que apenas ganharia maior visibilidade na cena internacional nos anos $60 \mathrm{e}$ 70".[9] Não é diverso o sentido do comentário de Luiz Camillo Osório: "Sua obra antecipou o que veio a ser um dos grandes trunfos da arte brasileira depois do neoconcretismo: um 'exercício experimental da liberdade"'.[10] Em 2010, na retrospectiva que organizou para o Museu de Arte Moderna de São Paulo, Rui Moreira Leite afirmou que o "artista representava uma ponte entre estes dois momentos fundamentais: o início da renovação nos anos 1920 e a vanguarda dos anos 1960”.[11] Recentemente, em entrevista para o site do Paço das Artes, Lúcio Agra assim o definiu, recordando e reiterando a dedicatória de Haroldo de Campos: "Flávio de Carvalho é o godfather da performance brasileira. Ele fez primeiro até mesmo o happening antes dos europeus e americanos, conforme bem afirma a dedicatória de Haroldo de Campos no lançamento da primeira edição da tradução de poemas de Maiakovski, com Boris Schnaiderman”.[12]

De fato, as ações de Flávio de Carvalho podem ser entendidas, em certa proporção, como antecipadoras de manifestações artísticas que, em anos posteriores, seriam chamadas de performances, happenings etc. Mas podemos nos perguntar: será apenas seu, muito justamente, propalado pioneirismo que faz de Flávio de Carvalho uma figura capaz de despertar cada vez mais interesse, sendo sempre mais lembrada e estudada na atualidade? É o caráter prenunciador de sua obra que o torna, em certa medida, nosso contemporâneo? Ou sua contemporaneidade não se resume a esse dom antecipatório?

Voltemos à cena inicial deste texto, deixando de lado, porém, o desfile isto é, a ação - e concentrando nossa atenção no traje apresentado por Flávio de Carvalho. Os dois conjuntos exibidos na tarde de 18 de outubro se constituíam basicamente de saia curta, blusa, chapéu, meia arrastão e sandália de couro cru. Pelas fotografias (infelizmente, todas em preto-e-branco) e pelos relatos da época, constata-se que as duas 
blusas eram muito parecidas; o que mudava era a cor: uma era vermelha, a outra, amarela - esta provavelmente a única peça original que restou daquela experiência. As blusas foram confeccionadas no que havia de mais moderno então, o nylon, e tinham o mesmo formato: gola branca franzida, que podia ser retirada, pregas no corpo e nas mangas ("pregas na blusa conservam a forma"[13]), mangas largas, franzidas no ombro, e base de abertura ampla (para "facilitar os movimentos" [14]). A vermelha exibia ainda, sobreposta ao nylon, uma cobertura de filó branco. As saias eram de algodão, cerca de quatro dedos acima dos joelhos, e se compunham igualmente de pregas, porém mais largas que as das blusas. A saia que combinava com a blusa vermelha era branca; a da blusa amarela, verde-garrafa. "O uso de uma grande variedade de cores", explicou Flávio de Carvalho, “tornar[á] os homens menos irascíveis e menos obtusos, mais plásticos e mais capazes de evoluir com maior velocidade." [15] Ao promover "maior alegria pelas cores e pelos movimentos livres", o novo traje acaba "afetando a psique do homem e possivelmente afetaria também o fluxo das guerras".[16] Afinal, "ninguém pode ser alegre enfiado numa roupa cinza, marrom ou azul marinho".[17] Complementava o traje um chapéu branco que, por ser também de nylon, era transparente e de estrutura pouco firme. A cabeça era, para Flávio de Carvalho, "a parte mais importante do corpo"[18], o local "de entrada e saída e de habitação da alma do homem" [19], por isso precisava ser protegida. Nos pés, em vez de sapatos fechados, sandálias de couro cru. Nas pernas, para esconder as varizes[20], meias arrastão, do feitio das que as atrizes do teatro musicado usavam - segundo a revista Manchete, Maria della Costa teria emprestado as meias que Flávio vestia.[21] "Alguns indivíduos complexados”, desabafou o artista à Folha da Manhã, "quiseram fazer piadinhas de mau gosto, mas não há nada demais em usar-se estas meias. As malhas largas provocam uma notável sensação de ventilação. [...] E quem não as quiser usar, que compre meias soquetes"[22].

Flávio de Carvalho batizou sua roupa de New Look, fazendo uma inequívoca referência ao famoso modelo criado por Christian Dior, quase dez anos antes, em 1947, em seu desfile de estreia como estilista. [23] Mas a indumentária também foi referida na época como "traje do futuro"[24], "roupa do futuro"[25], "fatiota futurista”[26], "smoking do 
futuro" [27]. O que era "novo", segundo o termo utilizado por Flávio, passou a ser qualificado, pelos outros, "do futuro"; ou seja, algo não para ser adotado no momento presente, mas somente em tempos vindouros. De fato, havia aspectos prenunciadores no traje proposto por Flávio de Carvalho. Em primeiro lugar, antecipou a invenção da minissaia: só uma década depois, Mary Quant a tornaria popular, mas reservando-a ainda, como a antiga saia, ao guarda-roupa feminino. Em segundo, previu, de certo modo, a equiparação dos modos de vestir masculino e feminino. Foi o próprio Flávio de Carvalho que, na conferência "Trajo e trópico", ministrada em 1967 na Universidade Federal de Pernambuco, a convite de seu amigo Gilberto Freyre, constatou: “A minha intenção de projetar um trajo adequado ao trópico era somente uma necessidade de modificação da indumentária, mas também era um prognóstico, foi um prognóstico feito onze anos atrás, de acontecimentos que estão se iniciando hoje".[28] De acordo com ele, esses acontecimentos - os modos de vestir masculino e feminino cada vez mais equânimes, o que levaria a uma moda unissex (não podemos deixar de lembrar, por exemplo, a difusão da calça jeans)[29] - terminariam por levar a "um nivelamento entre o homem e a mulher", que "vamos possivelmente presenciar em tempos futuros”.[30]

Contudo, se, por um lado, o New Look aponta para o futuro, por outro, ele acena para o passado. O próprio uso da saia curta por homens principal motivo de estranheza e crítica em relação ao traje - não era propriamente uma novidade. Respondendo a Cláudio Souto, um dos arguidores da conferência "Trajo e trópico" anteriormente citada, que alegou ser a calça um costume "profundamente arraigado" [31] no homem, Flávio de Carvalho observou:

O uso da calça não está preso ao homem, e a própria história da indumentária mostra que o homem não usava calças e a grande parte da história que já passou, que já se encontra no passado, o homem não usou calças. Usava o saiote, ou saia, ou então usava outra indumentária. A calça é tão recente na história da humanidade que praticamente ela não conta. Portanto, ela não está arraigada e presa ao homem teluricamente, como quis o jurista-sociólogo Cláudio Souto.[32] 
Quando apresentou seu traje aos jornalistas, em 1956, já havia alertado para a larga difusão da saia entre os homens ao longo da história: "Durante quinze mil anos, os homens de trinta dinastias egípcias usaram saiote e mesmo em nossos tempos escoceses e gregos ainda se trajam dessa forma".[33] Ainda no seminário promovido por Gilberto Freyre, retrucando o fisiólogo Nelson Chaves, que colocava em dúvida a masculinidade da roupa, disse ainda: "Os homens que usavam saiotes, na história, não eram efeminados. O saiote era usado pelo guerreiro grego, pelo romano [...] e por outros povos, inclusive pelos trabalhadores do engenho de Pernambuco no século dezenove e que não tinham nada de efeminados".[34] Não por acaso, algumas dessas figuras do passado foram evocadas pelos jornalistas quando da primeira aparição pública de Flávio de Carvalho envergando sua nova roupa. "O porte, com traje e tudo, parecia de um patrício romano ou de um imperador”, escreveu o repórter do Correio Popular.[35] Para a Folha da Manhã, o traje de Flávio sugeria uma mistura de personagens e de épocas: com seu ar sério, o artista, segundo o jornal, recordava "as estátuas dos senadores romanos", enquanto o chapéu de nylon branco "lembrava os que eram usados pelos espanhóis que conquistaram a América" e a gola era feita “no mais puro estilo renascença”.[36] Já O Cruzeiro via ali “um misto de roupa da Idade Média, com saiote e blusa rendada”.[37]

A saia, portanto, que, em princípio, parecia ser o aspecto do traje que mais claramente anunciava o porvir, era também o elemento que irrompia inesperadamente do passado - não do passado recente, que se confunde com o presente, em que os homens vestem mais comumente calças, mas de um passado mais remoto, que, na verdade, nunca se extinguiu de todo (haja vista, como o próprio Flávio destacou, as kilts escocesas). Talvez não seja casual a escolha do vermelho para uma das blusas da indumentária do artista, justamente aquela pertencente ao conjunto com o qual ele primeiro se apresentou à multidão. Além de indicar, conforme Flávio, coragem[38] e, por isso, ser “a cor dos heróis de todos os tempos", [39] o vermelho, entre todas as cores, teria sido aquela que mais se manteve viva e atuante, perpassando vários momentos da história: 
O herói grego de épocas micênicas usava uma clamyde vermelha, a cor vermelha era também do soldado romano e em toda a Idade Média, todo o Renascimento e até a Revolução Francesa, o vermelho (a púrpura) é a cor predominante na corte e frequentemente é privilégio somente de reis, príncipes e soldados.

O vermelho é a cor que predominava na bacia do Prata na época do agressivo ditador Rosas e o vermelho é encontrado nas calças dos soldados franceses em épocas recentes até 1914.[40]

Buscando transformar a roupa do presente, Flávio de Carvalho volta-se ao passado, mas não como um nostálgico. A sua intenção não era, em absoluto, reviver o passado como tal. "Acho que a consideração daquilo que apareceu no passado é sempre um gráfico daquilo que vai aparecer no futuro", afirmou em 1967.[41] Muito antes, em Os ossos do mundo, livro de 1936 que resultou de sua viagem a vários países da Europa entre 1934 e 1935 e no qual desenvolveu algo como uma arqueologia filosófica da cultura ocidental, já havia dito: "A luz sobre o passado é a única luz capaz de iluminar o presente, e de ajudar a derreter o véu da cegueira”. [42] Na compreensão de Flávio de Carvalho, o homem imerso em sua própria civilização se acha isolado pelos fatos. Falta-lhe distância para ser capaz de compreender realmente o que está à sua volta: “A ideia mesma de apreciação envolve viver fora do local, dos apreciadores de um certo local, já que aqueles que enxergam não são nunca os habitantes do local, pois que estes acostumados à visão diária do ambiente deixam de perceber as mutações do ambiente e o que ele possui de sugestivo".[43] Daí seu fascínio pela perspectiva que conquista o homem ao voar perspectiva, aliás, absolutamente nova naquela época: “A visão do homem em voo adquire mais uma dimensão sobre a visão do habitante da superfície; ele é capaz de prever e calcular o destino do habitante da superfície, o seu ponto de vista percorre o presente, o passado e o futuro desse personagem".[44] É deste mesmo tipo de visão que goza o homem diante de uma coleção, seja ela de um museu, de uma galeria, de um castelo etc.: "O observador, no museu, tem a claridade e a 'transparência' do homem em voo; não somente em algumas horas ele penetra em todas as fases que uma civilização levou séculos a desenvolver, mas pode, à vontade, aproximar-se ou distanciar-se dessa civilização, focalizando os detalhes com uma luminosidade super-realista, ou apagando-os numa 
nebulosa impressionista, e quase abstrata”.[45] Flávio encontra o passado precisamente nos objetos dessas coleções, nisso que ele denomina "ruínas" ou "ossos do mundo", nesses "resíduos abandonados pelo homem e não destruídos".[46] O próprio mundo se converte assim, aos seus olhos, numa espécie de coleção de coleções, que se trata de trazer à tona e investigar. Estaria aí a verdadeira vocação do arqueólogo, mas não do arqueólogo "bem comportado", e sim daquele "mal comportado", que "tem muito mais probabilidades de compreender o não-tempo", de penetrar nessas sucessivas camadas de história que formaram o indivíduo e que, ao serem recuperadas, são capazes de nos ajudar a entender o presente e também o futuro. Afinal, "a noção de tempo como a compreendemos parece nada significar numa sensibilíssima introspecção arqueológica, e o poder de sentir o passado e a espécie parece indicar a capacidade que tem o homem de viver fora do tempo".[47] Leitor de Nietzsche, de quem extrai a epígrafe para um dos principais textos de Os ossos do mundo e a quem queria erguer um templo,[48] Flávio parece estar evocando aqui algumas proposições da Segunda consideração intempestiva. Lê-se no texto nietzschiano que devemos atuar no tempo presente de maneira "intempestiva": "não saberia que sentido teria a filologia clássica em nossa época senão o de atuar nela de maneira intempestiva - ou seja, contra o tempo e, com isso, no tempo e, esperamos, em favor de um tempo vindouro".[49] Não podemos perder de vista também que o artista partilhava das convicções antropofágicas de seu amigo Oswald de Andrade e que a Antropofagia pressupunha uma visão "transversal" do processo histórico, como bem notou Benedito Nunes: "uma compreensão da História absorvida na préHistória, pelo que diz respeito ao passado, e dirigida a uma transistória, pelo que diz respeito ao futuro".[50] Também Oswald propôs, quase duas décadas depois das primeiras investigações arqueológicas de Flávio de Carvalho, que se criasse uma "ciência do vestígio errático", a "Errática".[51]

Para Flávio de Carvalho, o que está em questão não é o conhecimento do passado como passado; o passado só interessa enquanto força passível de ser ativada no presente. O presente é seu tempo e é nele que Flávio de Carvalho faz questão de atuar - até porque só nele, a rigor, se pode atuar. Na palestra que ministrou no Clubinho, no dia seguinte ao desfile do 
traje, Flávio frisou que seu traje "não [era] do futuro e sim do presente". [52] Preocupava-se com a moda do homem de seu tempo, e sua crítica se dirigia à persistência de um modo de vestir masculino incompatível com o clima tropical brasileiro: "A atual moda para homens é sobrevivência da calça, colete e pessoa do século XVII e possui ainda as cores sombrias e escuras derivadas da cor preta imposta à burguesia pela nobreza como condição depreciativa. Estas sobrevivências estão em desacordo com os conhecimentos atuais do homem e com o seu desenvolvimento cerebral". [53] O que Eduardo Sterzi observa em relação a Oswald Andrade poderia ser estendido a Flávio de Carvalho: "o pensamento de Oswald, que atravessa diferentes épocas e gêneros, adquire alguma unidade precisamente na ênfase que dá ao presente como tempo decisivo em que uma imagem do passado e uma imagem do futuro [...] são postas em contato".[54] A contemporaneidade de Flávio de Carvalho, portanto, não estaria no seu poder de antecipação, mas, sim, residiria na fusão de tempos que encontramos, por exemplo, em seu New Look. Como não se lembrar, a propósito, das considerações de Giorgio Agamben sobre o que é o contemporâneo e sobre como se constitui um ser humano que possa ser chamado de contemporâneo - considerações estas que, não esqueçamos, partem justamente da Segunda Consideração Intempestiva de Nietzsche:

Pertence verdadeiramente a seu tempo, é verdadeiramente contemporâneo aquele que não coincide perfeitamente com ele nem se adéqua às suas pretensões e é por isso, neste sentido, inatual; mas, justamente por isso, justamente através deste hiato [scarto] e deste anacronismo, ele é capaz mais do que os outros de perceber e apreender [afferrare] o seu tempo.[55]

Ao explicar o que propõe, Agamben parece ecoar as palavras de Flávio de Carvalho, artista que provavelmente desconhece: "Aqueles que coincidem muito plenamente com a época, que se ajustam em cada ponto perfeitamente a ela, não são contemporâneos porque, justamente por isso, não conseguem vê-la, não podem ter fixo o olhar sobre ela”.[56] E acrescenta: "A contemporaneidade se inscreve, de fato, no presente assinalando-o, antes de tudo, como arcaico e somente quem percebe no mais moderno e recente os índices e as assinalações [le segnature] do 
arcaico pode ser contemporâneo".[57] Curioso que, segundo Agamben, a via de acesso ao presente é também uma forma de arqueologia:

Os historiadores da literatura e da arte sabem que entre o arcaico e o moderno há um secreto encontro marcado [appuntamento segreto], e não tanto porque mesmo as formas mais arcaicas parecem exercitar sobre o presente um fascínio particular, quanto porque a chave do moderno está escondida no imemorial e no pré-histórico. Assim o mundo antigo em seu fim se volta, para se reencontrar, aos primórdios; a vanguarda, que se perdeu no tempo, persegue o primitivo e o arcaico. É neste sentido que se pode dizer que a via de acesso ao presente tem necessariamente a forma de uma arqueologia. [...] E ser contemporâneo significa, neste sentido, voltar a um presente em que não estamos mais.[58]

Em Flávio de Carvalho, "voltar a um presente em que não estamos mais" passa por provocar uma reação no presente no qual este seja levado a se reconhecer como ultrapassado, como anacrônico - não no sentido arqueológico-filosófico dessas palavras, mas no sentido corriqueiro, que nos diz de um conservadorismo que policia tanto os hábitos como roupas quanto os hábitos como práticas sociais. Não por acaso, também para Agamben a moda será objeto preferencial de reflexão, porque sintetiza, em si mesma, as noções de anacronismo e arqueologia: “O homem na moda, como o historiador, pode ler as assinalações do tempo somente se não se situa inteiramente no passado nem coincide sem resíduos com o presente, mas se acha, por assim dizer, na sua 'constelação', isto é, no lugar mesmo das assinalações”.[59]

[1] Bandeira, Manuel. O colete. In: Folha da Manhã, São Paulo, 28 out. 1956, p. 7.

[2] Apud Flávio de Carvalho exibiu o New Look para os intelectuais de Roma e de Paris. In: Folha da Noite, São Paulo, 4 fev. 1957, p. 10.

[3] Sangirardi Jr. garante que perguntara ao próprio Flávio de Carvalho qual fora sua primeira experiência, e este último teria lhe dito que consistira em, na fazenda de um parente, "fingir que estava se afogando e gritar desesperadamente por socorro". No entanto, sem ter conseguido chamar a atenção de alguém, a experiência resultou fracassada (Sangirardi Jr., Flávio de Carvalho, o revolucionário romântico. Rio de Janeiro: Philobiblion, 1985, p. 33). J. Toledo contesta Sangirardi Jr. e assegura que Flávio lhe declarara "enfaticamente" - e afirmara também "a vários repórteres" "não haver criado a 'Experiência ${ }^{\circ} 1$ "” e ter iniciado logo pela número dois "por um mero capricho de momento" (Toledo, J. Flávio de Carvalho: o comedor de emoções. São Paulo: Brasiliense; Campinas: Editora da Universidade Estadual de 


\begin{tabular}{l|l|l|l|l|}
\hline celeuna & número 4 maio 2014 \\
\hline
\end{tabular}

Campinas, 1994, p. 116). Para Luiz Carlos Daher, por sua vez, haverá sempre, quanto a esta questão, "um resíduo de mistério, pois Quirino da Silva e o próprio Flávio deram outras versões: ora a no 1 nunca existiu, ora Flávio 'não se lembrava' de qual teria sido, ora fora um estágio no Juqueri para estudar as expressões dos alienados, ora..." (Daher, Luiz Carlos. Flávio de Carvalho e a volúpia da forma. São Paulo: M.W. M Motores Diesel, 1984, p. 192).

[4] Este livro, com a dedicatória à mostra, estava em exibição na exposição Flávio de Carvalho, com curadoria de Rui Moreira Leite, realizada entre 15 de abril e 16 de junho de 2010 no Museu de Arte Moderna de São Paulo. O livro faz parte do Fundo Flávio de Carvalho, no CEDAE/UNICAMP.

[5] Pignatari, Décio. Contracomunicação. São Paulo: Perspectiva, 1973, 2a ed., p. 235.

[6] Apud Osório, Luiz Camillo. “Eu sou apenas um!”. As experiências de Flávio de Carvalho. In: Caderno Vídeo Brasil. São Paulo: SESC, 2005, p. 10.

[7] Zanini, Walter. "Introdução a Flávio de Carvalho". In: 17a Bienal de São Paulo - Catálogo geral. São Paulo: Fundação Bienal de São Paulo, 1983, p. 299.

[8] Muitas são as publicações e exposições dedicadas a Flávio de Carvalho ou que o tiveram como eixo condutor nos últimos anos: o destaque dado a ele nas coletivas MAM na Oca, em 2008, em São Paulo, e Sob um céu tropical, na galeria James Lisboa, em 2009, também em São Paulo, a retrospectiva do Museu de Arte Moderna de São Paulo, em 2010, com curadoria de Rui Moreira Leite, a sua aparição como figura-chave na mostra Desvíos de la deriva, no Museo Reina Sofía, também em 2010, com curadoria de Lisette Lagnado, a sua participação nas Bienal do Mercosul, em Porto Alegre, e 29a Bienal de São Paulo, em 2009 e 2010 respectivamente, a mostra individual Flávio de Carvalho - A revolução modernista no Brasil, em 2012, no Centro Cultural Banco do Brasil, de Brasília, a recente Flávio de Carvalho na coleção do MAB-FAAP, realizada entre novembro de $2013 \mathrm{e}$ janeiro de 2014, e a atualmente em cartaz na OCA, em São Paulo, Flávio de Carvalho: a experiência como obra; a reedição de Os ossos do mundo (São Paulo: Antiqua, 2005), a publicação de A moda e o novo homem (Rio de Janeiro: Azougue, 2010), os catálogos das exposições citadas e Flávio de Carvalho, o artista total, de Rui Moreira Leite (São Paulo: SENAC, 2008). Vale lembrar ainda o filme documentário A Deusa Branca, de Alceu França, realizado em 2013.

[9] Chiarelli, Tadeu. "Flávio de Carvalho: questões sobre sua arte de ação". In: Mattar, Denise (org). Flávio de Carvalho: 100 anos de um revolucionário romântico. Rio de Janeiro: CCBB, 1999, p. 53.

[10] Osório, Luiz Camillo. Flávio de Carvalho. São Paulo: Cosac Naify, 2000, p. 8.

[11] Moreira Leite, Rui. Flávio de Carvalho. São Paulo: Museu de Arte Moderna de São Paulo, 2010, p. 33.

[12] Performa Paço - Ações Externas. Entrevista com o curador Lúcio Agra. Disponível em:

http://www.pacodasartes.org.br/notas/entrevista performa lucioagra.aspx (http://www.pacodasartes.org.br/notas/entrevista performa lucioagra.aspx).

[13] Cf. Folheto que Flávio de Carvalho distribuiu em novembro de 1956, reproduzido em Mattar, Denise (org.). Flávio de Carvalho:100 anos de um revolucionário romântico cit., p. 55

[14] Idem.

[15] Apud Continua a provocar aplausos e vaias a roupa do homem do futuro. In: $O$ Dia, São Paulo 28 out. 1956.

[16] Idem.

[17] Flávio de Carvalho apud "Guerra às calças compridas". In: Diário Popular, São Paulo, 19 out. 1956 , p. 3.

[18] Carvalho, Flávio de. Os chapéus dos homens sem alma e os arquétipos dos mares pré-Cambrianos - Os homens pré-primitivos - A origem popular dos aristocráticos chapéus cônicos e cartola. In: A moda e o novo homem. Rio de Janeiro: Azougue, 2010, p. 227. 


\begin{tabular}{l|l|l|}
\hline celeuna número 4 maio 2014 & dossiê \\
\hline
\end{tabular}

[19] Carvalho, Flávio de. Sonho e realidade - Alma e chapéu - As idades púberes andam sem chapéu - O homem do século XXII. In: . A moda e o novo

homem cit., p. 219.]

[20] Carvalho, Flávio de. “Trajo e trópico”. In: Freyre, Gilberto (org.). Trópico \&. Recife: Universidade Federal de Pernambuco, 1967, p. 336.

[21] "Flávio de Carvalho estreou o seu new look". In: Manchete, Rio de Janeiro, 27 out. 1956 , p. 72.

[22] "Flávio de Carvalho apresentou ontem a sua versão para o "smoking" do futuro". In: Folha da Manhã, São Paulo, 20 out. 1956, p. 2.

[23] Com cintura marcada e ampla saia godê, o conjunto de Dior produziu uma revolução no guarda-roupa feminino, que, depois do fim da Segunda Guerra Mundial, tendia para as formas retas, mais masculinizadas.

[24] Cf. "Flávio de Carvalho apresentou ontem a sua versão para o 'smoking' do futuro” cit., p. 2; Jeremias. O traje do futuro. Folha da Noite, São Paulo, 24 out. 1956. E não esquecer que a festa realizada no Clubinho em 24 de outubro se chamou "Baile do Traje do Futuro".

[25] Cf. "Continua a provocar aplausos e vaias a roupa do futuro" cit.

[26] Cf. "Flávio de Carvalho apresentou ontem a sua versão para o 'smoking' do futuro" cit., p. 2.

[27] Cf. "Flávio de Carvalho apresentou ontem a sua versão para o 'smoking' do futuro" cit., p. 2.

[28] Carvalho, Flávio de. “Trajo e trópico” cit., p. 335.

[29] Idem, p. 382.

[30] Idem, p. 336.

[31] Souto, Cláudio. “Trajo e trópico” cit., p. 365.

[32] Carvalho, Flávio de. “Trajo e trópico” cit., p. 386.

[33] Flávio de Carvalho apud "Flávio de Carvalho lançou ontem o revolucionário "traje do futuro"”. In: Folha da Manhã, São Paulo, 19 out. 1956. Cf. também

"Guerra às calças compridas" cit., p. 3; e "Flávio de Carvalho apresentou ontem a sua versão para o 'smoking' do futuro" cit., p. 2.

[34] Carvalho, Flávio de. "Trajo e trópico" cit., p. 378.

[35] "De calção e blusa Flávio de Carvalho surpreendeu a cidade com outra experiência”. Correio Popular, 19 out. 1956, p. 2.

[36] "Flávio de Carvalho lançou ontem o revolucionário 'traje do futuro" cit.

[37] “As saias de Flávio”. In: O Cruzeiro, 10 nov. 1956, p. 137.

[38] Quando quer se proteger, explica Flávio de Carvalho no oitavo artigo de $A$ moda e o novo homem, o homem busca, como a borboleta, se fundir, pelo mimetismo da cor, ao ambiente. Porém, quando sai para enfrentar seus iguais, comporta-se de outro modo: "o seu desejo é exibir a sua coragem e o seu valor porque ele sabe que o seu semelhante - ao contrário da fera - pode ser vencido por motivos de igualdade de condições". Daí, ele escolher o vermelho - como o vermelho de seu blusão: "é a cor que mais chama a atenção" (Carvalho, Flávio de. Um grave erro - A moda do rio Araguaia - Ornamento e defesa - A escolha da cor. In: _. A moda e novo homem cit., p. 44).

[39] Carvalho, Flávio de. "Trajo e trópico" cit., p. 330.

[40] Carvalho, Flávio de. Um grave erro - A moda do rio Araguaia - Ornamento e defesa - A escolha da cor cit., p. 44.

[41] Carvalho, Flávio de. “Trajo e trópico" cit., p. 388.

[42] Carvalho, Flávio de. “As ruínas do mundo". In:

São Paulo: Antiqua, 2005, p. 42.

[43] Carvalho, Flávio de. "As ruínas do mundo" cit., p. 41.

[44] Carvalho, Flávio de. "Voando sobre as Costas Brasileiras" e "Notas sobre a sensação do medo”. In: Os ossos do mundo cit., p. 15.

[45] Carvalho, Flávio de. “As ruínas do mundo" cit., p. 41.

[46] Idem, p. 43.

[47] Idem, p. 48. 


\begin{tabular}{l|l|l|l|l|}
\hline celeuna & número 4 maio 2014 \\
\hline
\end{tabular}

[48] Cf. Zanini, Walter. "Introdução a Flávio de Carvalho" cit., p. 296.

[49] Nietzsche, Friedrich. Segunda consideração intempestiva. Trad. Marco Antônio Canova. Rio de Janeiro: Relume Dumará, 2003, p. 7.

[50] Nunes, Benedito. “Antropofagia ao alcance de todos”. In: Andrade, Oswald. A utopia antropofágica. São Paulo: Globo e Secretaria de Estado da Cultura, 1990, p. 27.

[51] Cf. Andrade, Oswald. "A crise da filosofia messiânica”. In: A utopia antropofágica cit., p. 111.

[52] "Flávio de Carvalho exibe seu traje no Clube dos Artistas". In: Folha da Tarde, São Paulo, 20 out. 1956.

[53] Carvalho, Flávio de. "Moda de verão para a cidade". In: Diário de S. Paulo, 24 jun. 1956, reproduzido em Carvalho, Flávio de. A moda e o novo homem. São Paulo: SESC/SENAC, 1992, p. 66.

[54] Sterzi, Eduardo. A prova dos nove: alguma poesia moderna e a tarefa da alegria. São Paulo: Lume, 2008, p. 56.

[55] Agamben, Giorgio. Che cos'è il contemporaneo?. Roma: Nottetempo, 2008, pp. 8-9.

[56] Idem, pp. 9-10.

[57] Idem, pp. 20-21.

[58] Idem, pp. 21-22.

[59] Giorgio Agamben, Signatura rerum: sul metodo. Torino: Bollati Boringhieri, 2008, p. 75.

VERONICA STIGGER é escritora, crítica de arte e professora universitária. Lançou recentemente o romance Opisanie swiata (Cosac Naify). 